\title{
ESPAÇO ECONÔMICO
}

\section{Eliseu Savério Sposito}

Universidade Estadual Paulista Júlio de Mesquita Filho (UNESP)
O espaço pode ser interpretado como conceito no plano da teoria, como categoria no plano do método ou mesmo ter conotação em diferentes escalas no senso comum. Neste caso, tratá-lo-emos como conceito, partindo do pressuposto de que, quando adjetivamos o espaço (como espaço econômico) ele se torna um produto do intelecto humano porque é uma decorrência teórica da elaboração de seu alcance, seu tempo, seu contorno e sua força teórica.

O espaço econômico não foi conceituado, mas há indícios, a partir do que escreveram inúmeros geógrafos e não geógrafos, de que ele se define por ser o espaço das empresas (das firmas) ou das conotações geopolíticas. $\mathrm{Na}$ tentativa de teorizar o espaço econômico, partimos da ideia de que ele é a empiricização do espaço pois é, no plano empírico, que ele se instaura a partir das lógicas dos modos de produção e das estratégias econômicas e espaciais das empresas.

Para ilustrar tal empiricização, começamos pelas conotações geopolíticas, a partir de um exemplo. O Espaço Econômico Europeu (EEE) é uma área que foi criada, em 1994, por meio de decisões políticas dos Estados europeus, para facilitar a circulação de bens, capitais e pessoas, em termos do livre comércio, que se constituiu, formalmente, como a União Europeia. Os acordos que geraram o EEE foram feitos pelos Estados-Membros da Associação Europeia de Livro Comércio (EFTA) para atender, atualmente, quase 500 milhões de consumidores. Com isso, as fronteiras ficaram livres de trâmites aduaneiros e se ampliou, nas últimas décadas, com a adesão de ouros Estados-nação, chegando a 28 países.

0 espaço econômico pode se referir, também, ao espaço das empresas que representam as mudanças contemporâneas sendo enfocado, por elas, até mesmo como dimensão estratégica. Assim, o espaço econômico foi produto histórico das lógicas e estratégias de localização das empresas, principalmente depois da primeira revolução industrial. As características do espaço econômico podem ser encontradas nos fatores de localização industrial que remontam ao século XIX, quando Von Thünen elaborou a teoria dos círculos concêntricos (ou teoria do Estado isolado, autossuficiente e plano), em área com predominância econômica da agricultura. Para ele, no centro se localizava a cidade, circundada por círculos concêntricos ocupados por atividades agrícolas distintas, desde os produtos mais perecíveis e de produção intensiva (hortifrutigranjeiros) até aqueles com maior resistência à deterioração, conformando o primeiro círculo. No segundo, seria produzida a lenha (combustível importante antes da industrialização); no terceiro, seriam produzidos os grãos e, por fim, a produção pecuária. Mesmo que o modelo tenha sido elaborado antes do surgimento das ferrovias e rodovias, ele ainda é uma contribuição teórica importante porque se baseava no princípio da maximização de lucros e pode ser considerado como fundamento do espaço econômico.

A alusão ao modelo de Von Thünen permite ir além, porque o capital, a terra e o trabalho, os três elementos fundamentais no sistema capitalista, associados ao papel dos transportes, da fertilidade da terra e dos custos efetivos dos produtos, conformam os mercados que, por sua vez, também dão o desenho do espaço econômico de uma região, país ou conjunto de países. Neste caso, não se pode falar do mundo inteiro porque os espaços econômicos são balizados, também, pelas formações econômico-sociais com suas inúmeras determinações.

Outros cientistas também se ocuparam de teorizar, na busca de modelos, a localização das indústrias ou, mais amplamente, das atividades econômicas, mediante a configuração, em seu tempo, da divisão do trabalho. Weber (no início do século XX) supõe mão de obra constante e espaço homogêneo, partindo das necessidades da empresa na busca, sempre do preço de produção mais baixo, valorizando o custo de transporte, o peso e a distância. Lösch, no final da década de 1930, parte da demanda como a principal variável espacial e raciocina 
a partir da localização mais adequada para a minimização dos custos de transporte e a maximização dos ganhos. Isard, na década de 1950, procurou combinar os modelos elaborados anteriormente baseando-se em estudos empíricos para mostrar que as empresas buscam as localizações que maximizam seus benefícios. Mais recentemente, Camagni (início do século XXI) elaborou suas explicações teóricas para o espaço econômico a partir de outras determinações que elegeu como a aglomeração, que favorece a localização por proximidade; a acessibilidade, que se refere à superação de dificuldades espaciais ao movimento de pessoas e mercadorias, e ao intercâmbio de bens, serviços e informações; a interação espacial que se refere ao desenvolvimento de rede complexa de relações bidirecionais ao redor dos principais focos econômicos; e introduz o papel da competivividade, fator que fortalece o nível hierárquico na rede urbana mediante processos de integração horizontal ou vertical, gerando sinergias e complementaridades.

O espaço econômico é resultado, portanto, da dinâmica de redes de fluxos visíveis (mercadorias e pessoas) e invisíveis (capital, informação e tecnologia) que se articulam nas relações de produção, consumo e gestão dos negócios.

A evolução dos modelos, desde a primeira interpretação de Von Thünen, são construções teóricas desde uma área que não tinha passado por um processo de industrialização, como ocorrera com a Inglaterra a partir do século XVII, até se chegar, no início do século XXI, ao regime de acumulação flexível e de mundialização do capital. Para George (1973), o desenvolvimento industrial daquele país foi tão forte porque despojou a produção agrícola de população ativa para concentrar todos os esforços na produção industrial. A existência de minérios de carvão (fator essencial na industrialização e nos transportes - como fonte de energia para fábricas, ferrovias e navios) e de ferro provoca a repartição geográfica das indústrias inglesas, aliada à atividade do comércio marítimo. E como ele era essencial para os processos industriais, sua exportação para todos os continentes ampliou os horizontes do espaço econômico. Assim, podemos afirmar que o espaço econômico inglês se manifestava diferenciando (e ao mesmo tempo articulando) a cidade e o campo, a indústria e a agricultura, e os portos e o comércio marítimo. Essa configuração lembra o que Smith (1988) demonstrou a partir da relação sociedade-natureza: a distribuição desigual dos recursos naturais é fundamento para a desigualdade entre as diferentes áreas dentro dos países e entre países, o que leva à diferenciação geográfica entre eles.

Outro aspecto a ser destacado é o fato de que a transformação da natureza em recursos foi decorrente da capacidade que a humanidade teve em dominar as forças naturais. Se não se pode falar em espaço econômico decorrente apenas das instalações de moinhos na Holanda, onde o vento sopra constantemente por causa do relevo plano do país, quando ele se torna fundamental em seus objetivos produtivos, como moer (para a produção do trigo), serrar (madeira) e bombear as águas dos diques, além de servir de força motor para a produção de óleo e papel e, portanto, para a indústria, ele vem a ser o ícone da formação de um espaço econômico. Com o advento da industrialização, essa força motriz foi importante para a produção de placas de metal. 0 espaço econômico holandês, portanto, foi se construindo com e pela presença dos moinhos. Tomando esse exemplo como premissa, podemos afirmar que não se deve confundir o espaço econômico com a produção da natureza ou, em outros termos, de maneira mais abrangente, com o espaço natural, embora aquele se baseie nas condições oferecidas por este e sem ele não possa se constituir.

O espaço econômico pode ser enfocado, também, em diferentes escalas. Na escala internacional, no século $\mathrm{XX}$, a presença de recursos naturais como petróleo, estanho, manganês, cromo, níquel e cobre, desenha-o com densidades diferentes para a acumulação capitalista das empresas. É, portanto, o espaço das firmas que se projeta como espaço econômico. Esses recursos permitem o surgimento de países industriais novos em relação aos europeus, modificando o comércio internacional entre eles. Novas áreas que se industrializam se evidenciam em escalas nacionais e até mesmo regionais, com densidades diferentes, intra ou entre fronteiras, de apropriação dos recursos naturais, de instauração do processo industrial por meio de firmas de diferentes tamanhos. Em decorrência disso, há redistribuição da população, caracterizada como força de trabalho e como consumidora de bens produzidos pelos clássicos setores primário e secundário da economia.

No século $X X$, quando ocorreram duas guerras mundiais, houve desequilíbrios em relação à dinâmica anterior, com a segmentação da unidade do mercado mundial de matérias-primas (com o empobrecimento dos países envolvidos nas guerras e a mudança do foco de acumulação, passando da Europa para os Estados Unidos) e com a formação de monopólios, a diversificação dos sistemas econômicos (emergência dos países chamados subdesenvolvidos com seus processos específicos de industrialização) e, mais recentemente, com as transformações nos regimes de acumulação.

Aqui, voltamos à abordagem geopolítica dos espaços econômicos. No final do século XX, o espaço econômico mundial caracterizava-se por algumas áreas identifi- 
cadas com alto poder de consumo (como a megalópole norte-americana, a Europa e o Japão). Por outro lado, a produção de cereais evidenciava-se no meio-oeste dos Estados Unidos, no sudeste da América do Sul e sul da Austrália. A produção de petróleo já conformava o espaço econômico das grandes empresas petrolíferas, constituído pelo Texas, Venezuela, Oriente Médio e Indonésia. O espaço econômico evidenciado pela produção agropecuária tinha a Argentina, a África do Sul como importantes produtores de lã, as carnes no Brasil, na Argentina, na Austrália, na África do Sul e nos Estados Unidos. Além disso havia, também, outros produtos importantes, como os minérios, os metais não ferrosos, o algodão, as bebidas, os óleos e frutas tropicais produzidos em diferentes países.

O espaço econômico das firmas decorre de suas dinâmicas e estratégias que se realizam por meio de ações espaciais e políticas, conformando as lógicas para suas atuações. Estas têm o poder de influenciar na reestruturação da rede urbana na combinação entre situação geográfica e nível de complexidade de seus papeis e funções, em virtude das possibilidades de ampliar, por meio do consumo, o alcance espacial de sua reprodução econômica.

Há duas tendências na divisão do trabalho: uma primeira pode ser identificada com as estratégias, em escalas de grande abrangência de regiões, para a valorização e a rentabilidade definidas pelas empresas e, a segunda, que exprime as forças das ligações existentes com as qualidades de um território, o que se refere, diretamente, aos seus estabelecimentos, unidades inscritas no espaço econômico. Por isso, o espaço econômico pode ser moldado, também, pela eficácia das atividades das empresas, principalmente aquelas consideradas multi ou transnacionais.

O espaço das firmas, com a mudança no regime de acumulação (do fordismo para a acumulação flexível), caracteriza-se, também, pela disjunção funcional decorrente, principalmente, dos custos de localização que levam a uma seleção espacial na implantação dos estabelecimentos industriais; dos custos salariais e do custo de reprodução da força de trabalho em relação ao custo total da produção; da transferência para áreas periféricas com componentes mais baratos para a produção. Essas características (que formam pares contraditórios que se interpenetram) mostram que a disjunção funcional se apoia na segmentação técnica do trabalho decorrente do tipo de atividade, do conteúdo social e dos níveis de qualidade requeridos.

Em resumo, o espaço econômico configura-se por meio da contradição entre cidade e o campo, a indústria e a agricultura, os portos e o comércio marítimo, a produ- ção e o consumo, a existência de matérias-primas e sua utilização como recursos e, do ponto de vista da formação econômico-social, pelas características da divisão territorial e da divisão internacional do trabalho.

Por último, podemos afirmar que o espaço econômico se constitui qualitativa e quantitativamente e esse aspecto aponta para novas possibilidades de investigação e interpretação. Com a intensificação das tecnologias por meio da internet e dos aparelhos individuais (telefone celular) cabe ampliar seu entendimento considerando a escala do indivíduo e de seu cotidiano, além de levar em conta as novas características de classe no mundo capitalista e as novas formas de consumo. Esses indicadores poderão concorrer para outro entendimento do que pode ser o espaço econômico e, portanto, como as diferentes formas de inovação o transformam. Em outras palavras, como as novas tecnologias podem ter diferentes efeitos sobre o espaço econômico não a partir da escala das firmas, mas a partir do indivíduo e de seu cotidiano.

\section{REFERÊNCIAS}

CAMAGNI, Roberto. El principio de aglomeración (o de la sinergia); El principio de interacción espacial (o de la demanda de movilidad y de contactos). In: Economía urbana. Barcelona: Antonio Bosh, p.21-50, p.78-96, 2005.

FIRKOWSKI, Olga C.; SPOSITO, Eliseu S. Indústria, ordenamento do território e transportes. A contribuição de André Fischer. São Paulo: Expressão Popular, 2008.

FISCHER, André. Industrie et espace géographique. Paris: Masson, 1994.

GEORGE, Pierre. Geografia industrial do mundo. São Paulo: Difel, 1973.

MANZAGOL, Claude. Lógica do espaço industrial. São Paulo: Difel, 1985.

SMITH, Neil. Desenvolvimento desigual. Rio de Janeiro: Bertrand Brasil, 1988. 